S1 Appendix. Data collection tools (Questionnaires) 


\section{QUESTIONNAIRE FOR FARMERS.}

\section{A. Environmental Hygiene conditions}

1. Where do you normally defaecate when at work on the farm?

Public toilet ( ) toilet on the farm premises ( ) A neighbour's toilet ( ) Open Defaecation ( )

2. What is your source of drinking water when working on the farm? (Tick all responses) Sachet water ( ) Bottled mineral water ( ) Piped water ( ) Water from home ( )

\section{B. Food Hygiene practices}

3. How many times do you eat when at work? Once ( ) 2 times ( ) 3 times ( ) More than 3 times ( )

4. What is the source of the food you normally eat when at work?

Food from home ( ) street food ( ) local restaurant food ( ) prepared food on farm ( ) Other ( )

5. Which of these do you do most?

Eating at the farm ( ) Eating at the food vending site ( ) Eating at home ( ) Other ( )

6. Do you normally wash your hands before eating at the farm site?

Yes ( ) No ( )

7. If Yes, what do you wash your hands with?

Irrigation Water only (Specify)....

Pipe water only ( ) Sachet Water only ( )

Soap and water ( )

C. Health Risk Perceptions and Awareness

8. Are you aware of any health risks associated with farming practices using drain water? Yes ( ) No ( )

9. If yes, what kind of health risk do you know of?

List all of them.

10. What do you do to protect yourself from these health risks?

List them.

D. Socio-economic issues

11. Does the use of drain water/dug-out water for irrigation increase your income as compared to the use of piped water?

Yes ( ) No ( ) Cannot tell ( )

12. Is farming the main source of your income? Yes $($ ) No ( )

13. How much time do you spend on the farm?

14. If you have any other job, how much time do you spend at:

Farm.

Other job (s).

15. How many people depend on you?

E. Personal Information

16. Sex Male ( ) Female ( )

17. Age $\square$

18. Religion Christian ( ) Moslem ( ) Traditional worshipper ( ) Other ( )

19. Educational background: No formal education ( ) Primary education ( ) JHS/MS ( ) SHS/A-level ( ) Polytechnic/University ( )

Date:

Enumerator ID:
Time:

Location ID: 


\section{Appendix B. Questionnaire for market vendors}

\section{QUESTIONNAIRE FOR MARKET VENDORS}

\section{A. Produce Hygiene conditions}

1. Where do you normally store your produce before selling them?

At the market ( ) At home ( ) other ( ) specify

2. How do you normally store the following vegetables before selling them? (Indicate in the table below):

\begin{tabular}{|c|c|}
\hline Vegetables & How storage is done \\
\hline a) Lettuce & \\
\hline b) Carrots & \\
\hline c) Spring Onions & \\
\hline d) Cabbage & \\
\hline
\end{tabular}

In a sack ( ) In a basket ( ) On a table but covered ( )

In a box ( ) Other ( ) specify.

3. Where do you normally display your vegetables for sale? (Indicate in the table below):

\begin{tabular}{|l|l|}
\hline Vegetables & How produce is displayed \\
\hline a) Lettuce & \\
\hline b) Carrots & \\
\hline c) Spring Onions & \\
\hline d) Cabbage & \\
\hline \multicolumn{2}{|c|}{ Table top ( ) Basket/bowl ( ) material on ground ( ) bare ground ( ) }
\end{tabular}

4. Do you wash the vegetables before sales?

Yes ( ) No( )

5. If yes, what is the source of water for washing the vegetables?

Piped water ( ) well water ( ) Tanker services ( ) Other (specify)

6. How much time do you spend on the following activities daily

\begin{tabular}{|l|l|}
\hline Activity & Time Spent \\
\hline a) Washing of lettuce & \\
\hline b) Washing of carrot & \\
\hline $\begin{array}{l}\text { c) Cutting or removal of waste parts of } \\
\text { cabbages }\end{array}$ & \\
\hline d) Removal of waste parts of spring onions & \\
\hline
\end{tabular}

7. Are customers normally happy with the quality of vegetables sold at the market?

Yes ( ) No ( )

8. What do customers normally complain of when at the market?

Write complaints

B. Environmental Hygiene conditions

9. Where do you normally defaecate when you are at the market?

Public toilet ( ) Market toilet ( ) In a polythene bag ( ) Open Defaecation ( ) 
10. What is your source of drinking water when working at the market? Sachet water () Bottled mineral water ( ) Piped water ( ) Water from home ( )

11. Are you normally satisfied with refuse collection and management at the market? Yes ( ) No( )

12. If No, what are you not satisfied with? Write down reason (s).

13. Are you generally satisfied with drainage management at the market? Yes ( ) No( )

14. If No, what are you not satisfied with? Write down reason (s)

\section{Hand washing and food Hygiene practices}

15. How many times do you eat when at the market? Once ( ) 2 times ( ) 3 times ( ) more than 3 times ( )

16. What is the source of the food you normally eat when at the Market?

Food from home ( ) street food ( ) local restaurant food ( ) Other ( ) specify.

17. Do you normally wash your hands when eating at the market? Yes ( ) No()

18. If Yes, what do you wash your hands with?

Only water ( ) Soap and water ( )

D. Health Risk Awareness and Perceptions

19. Where do you buy the vegetables you sell from?
Farm gate (
Wholesale market ( )
Retail Market ( ) Other ( )

20. If farm gate, do you have any reason (s) why you buy from these farm gates?

Yes ( ) No ( )

21. If yes, what are your reasons?

List reasons.

22. Do you know of the source of water farmers use to irrigate their crops?

Yes ( ) No( )

23. If you know the source is drain water, would you still buy the vegetables?

Yes ( ) No( )

List reasons for Yes or No answer.

24. Are you aware of any health risks associated with the consumption of vegetables that are irrigated with drain water? Yes ( ) No ( )

25. If Yes, what health risks do you know of?

List health risks.

26. Do you consume some of the vegetables yourself? Yes ( ) No ( )

27. If you use the vegetables yourself, how many times in a week do you consume them uncooked (i.e. prepare it as salad)?

28. How much of the following vegetables do you use to prepare salad for one meal?

\begin{tabular}{|l|l|}
\hline Vegetable & Quantity used \\
\hline a) Lettuce & \\
\hline b) Cabbage & \\
\hline c) Spring Onion & \\
\hline d) Carrot & \\
\hline
\end{tabular}


E. Personal Background

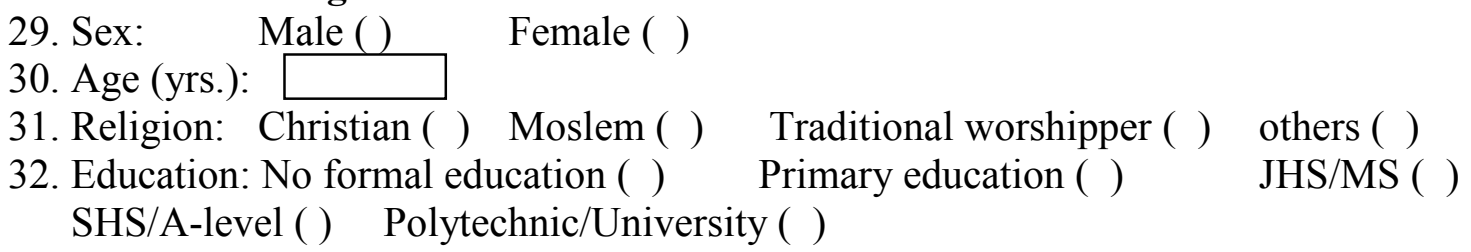

Date:

Time:

Enumerator ID:

Location ID: 


\section{Appendix C. Questionnaire for produce buyers at markets (Domestic consumers)}

\section{QUESTIONNAIRE FOR PRODUCE BUYERS (MARKET)}

\section{A. Consumption Patterns}

1. Which of these vegetables do you normally buy most at the market? Lettuce ( ) Carrot ( ) Spring onion ( ) cabbage ( )

2. How often in a week do you buy lettuce/cabbage from the market?

3. What do you normally do at home to clean these vegetables? Wash with clean water ( ) Wash in salt water ( ) Add a disinfectant ( ) Other ( ) Specify.

4. Mostly, do you consume these vegetables cooked or uncooked? Cooked ( ) Uncooked ( )

5. If vegetables are sometimes consumed uncooked, how often in a week is this done (i.e. consumed as salad)?

6. On average, how many of these vegetables do you use for one salad meal in a day?
a). Lettuce
b). Cabbage
c). Spring Onion
d). Carrot

7. How many people in the house consume the salad in a day?

B. Health Risk Awareness and Perceptions

8. Are you aware of the source of the vegetables you buy at the market? Yes ( ) No ( )

9. What is the main reason why you buy from this market vendor and not from others? Write down the main reason.

10. Do you think the source of water farmers use to irrigate the vegetables could have influence on your decision to buy them? Yes ( ) No ( )

11. Would you still buy these produce or not if you were aware that it was irrigated with wastewater (drain water)? Buy ( ) Not buy ( )

12. Are you aware of any health risks associated with the consumption of produce that are irrigated with wastewater? Yes ( ) No ( )

13. If Yes, what are the main health risks/disease you know of?

Write down main health risks mentioned.

14. Have you had diarrhoea within 2 weeks after consuming salads before?

Yes ( ) No ( ) cannot remember ( )

\section{Environmental Conditions and Health Status}

15. Are you generally satisfied with how produce are displayed for sale at the markets? Yes ( ) No ( )

16. Are you satisfied with the general environmental conditions at the produce vending site? Yes ( ) No ( )

17. If No, can you give reasons?

18. What do you think can be done by market vendors to improve environmental sanitation at the market?

Write down responses 
19. What do you think can be done by the government to improve environmental sanitation conditions at the market?

Write down responses.

\section{Personal Background}

20. Sex: $\quad$ Male () Female ( )

21. Age (yrs.):

22. Religion: Christian ( ) Moslem ( ) Traditional worshipper ( ) others ( )

23. Occupation: Government/Office worker ( ) Trading ( ) Vocational ( ) Other ( )

Enumerator ID:

Location ID:

Date: 


\section{Appendix D. Questionnaire for street food vendors}

\section{QUESTIONNAIRE FOR STREET FOOD VENDORS}

\section{A. Selling information}

1. How many days in a week do you normally sell cooked rice/other food with salad?

2. On average, how much of these vegetables do you use to prepare salad for a day?
a). Lettuce
b). Cabbage
c). Carrot
d). Spring Onion

3. On average, how many customers buy rice with salad in a day?

4. How much time do you spend selling food at your vending site?

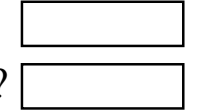

5. What do you normally do when less busy at your vending site?

Chatting with friends ( ) Washing of utensils ( ) wait for customers ( )

Other ( ) Specify.

\section{B. Produce and Food Hygiene Practices}

6. Where do you normally store the produce before using them for salad?
At home ( )
At vending site ( )
use it immediately after buying ( )

Other (Specify)

7. How do you store the produce? On the bare ground ( ) On a mat on the ground ( ) In a box or container ( ) Other (Specify)

8. Where do you normally prepare the salad?
At home ( )
At vending site ( $)$
Other ( ) Specify

9. What do you normally do to clean the vegetables before salad preparation?

Wash with clean water $($ ) Wash in salt water () Use a disinfectant

(Vinegar).................. Other (Specify)......

10. What is the source of water for washing the produce before salad preparation?

Piped water ( ) well water ( ) Tanker services ( ) Other ( ).

11. Do you normally wash your hands before salad preparation? Yes ( ) No ( )

12. If Yes, what do you use to wash your hands? Only water ( ) Water and Soap ( ) Other ( )

13. What is your normal practice of serving the salad to consumers?

Bare hands ( ) Hand covered with a polythene bag ( ) Spoon/ladle ( ) Other ( )

\section{Environmental Hygiene conditions}

14. Where do you normally defaecate when you are at work on the farm?
Public toilet ( )
Neighbour's/friend's toilet ( )
In a polythene bag (
Open
Defaecation ( )

\section{Health Risk Awareness}

15. Where do you normally buy the vegetables you use to prepare the salad from?
Farm gate ( )
Wholesale market ( )
Retail Market ( )

16. If farm gate, do you have any reason (s) why you buy from these farm gates? Yes ( ) No ( )

17. If yes, what are your reasons?

List reasons.

18. Are you aware of the source of water farmers use to irrigate their crops? 
Yes ( ) No( )

19. If you know the source is drain water, would you still buy these vegetables?

Yes ( ) No( )

20. If yes, could you provide some reasons

21. If No, could you provide some reasons

22. Are you aware of any health risks associated with the consumption of vegetable salads that are irrigated with wastewater? Yes ( )

23. If Yes, what health risks do you know of? List health risks.

24. Do you consume some of the salads yourself? Yes ( ) No ( )

25. If yes, how often in a week do you consume them?

26. Have you had any diarrhoea disease within 2 weeks after consuming salad foods? Yes ( ) No ( ) cannot remember ( )

E. Personal Background

27. Sex

28. Age (yrs.)

Male ( )

Female ( )

29. Religion Christian ( ) Moslem ( ) Traditional worshipper ( ) others ( )

30. Education: No formal education ( ) Primary education ( ) JHS/MS ( ) SHS/Alevel ( ) Polytechnic/University ( )

31. Do you do any other work apart from street food vending? Yes ( ) No ( )

32. If Yes, how much time do you spend on each of them?

Street food vending.

Other jobs. 


\section{Appendix E. Questionnaire for street food consumers}

\section{QUESTIONNAIRE FOR STREET FOOD CONSUMERS}

\section{A. Consumption Patterns}

1. Do you normally take the salad or only the rice? Yes, I take ( ) No, I do not take ( )

2. If No, do you have any reasons why you don't take the salad?

Write down reason(s).

3. If you take the salad, how often in a week do you normally consume street salad food ("check-check"/others)?

4. What makes you prefer to buy and consume street foods with salad? (tick all answers) Cheap ( ) Convenient ( ) I just like it ( ) Other (specify).....

B. Health Risk Awareness and Perceptions

5. Does anything influence your decision to buy the food from one seller and not the other? Write down the main reason.

6. Are you aware of the source of water used to irrigate the vegetables used for the salad? Yes ( ) No ( )

7. Would you still buy or take the salad if you were aware that the vegetables used to prepare it were irrigated with drain water? Buy ( ) Not buy ( )

8. Are you aware of any health risks associated with the consumption of salad prepared from vegetables that are irrigated with drain water? Yes ( ) No ( )

9. If Yes, what is the main health risk/disease you know of? Write down the main health risk/disease mentioned

\section{Environmental Conditions and Health Status}

10. Are you generally satisfied with how the salads are prepared? Yes ( ) No ( ) don't know how they are prepared ( ) Other ( )

11. Are you satisfied with the general environmental conditions at the food vending site? Yes ( ) No ( )

12. If No, what do you think can be done to improve the environmental sanitation conditions at the vending sites?.

13. Have you ever had diarrhoea disease within 2 weeks after consuming lettuce salads? Yes ( ) No ( ) cannot remember ( )

D. Personal Background

14. Sex: Male ( ) Female ( )

15. Age (yrs.):

16. Religion: Christian ( ) Moslem ( ) Traditional worshipper ( ) others ( )

17. Occupation: Government/Office worker ( ) Trading ( ) Vocational ( ) Other (specify)

\section{Enumerator ID}

Location ID

Date 